\title{
Optimization of chemical aids in the process of deinking sludge thickening
}

\author{
Jacek Czechowski, Konrad Olejnik \\ Technical University of Lodz, Institute of Papermaking and Printing, ul. Wólczańska 223, 90-924 Łódź, Poland, \\ e-mail: konrad.olejnik@p.lodz.pl
}

\begin{abstract}
The authors have analyzed a modern technological line of the latest chemicals for the recovered paper processing and de-inking in terms of reducing the amount of wastes arising during the production. The authors have also investigated the effectiveness of selected chemical aids (coagulants and flocculants) supporting the process of sludge dewatering. 12 different types of flocculants were tested. The best chemical agent was selected as well as its optimal dosage. The highest dynamics of sludge dewatering improvement (expressed by the dewatering time under standard conditions) was observed with the ECR3 agent dosage of $6-6.5 \mathrm{~kg}$ per tonne of the absolutely dry sludge. Long-term analyses of the tested line have proved that the retention aid and its dosage were selected correctly.
\end{abstract}

Keywords: paper, recovered paper, retention agents, waste, sludge, recycling.

Presented at VII Conference Wasteless Technologies and Waste Management in Chemical Industry and Agriculture, Międzyzdroje, 12 - 15 June, 2007.

\section{INTRODUCTION}

In order to minimize the negative impact on the natural environment, the latest technologies for the recovered paper processing use a wide range of modern chemicals, mainly the retention agents. Application of those agents in papermaking brings significant technological, economic and environmental benefits which are achieved owing to high retention of the fillers, fines and other more and more diverse and valuable components of papermaking stock with an additional acceleration of paper web de-watering and clarification of waste water. The effective operation of water system in a modern paper mill is impossible without an application of coagulant and flocculent agents ${ }^{\mathbf{1}}$.

Papermaking effluent is a complex physical and chemical system, consisting of a solid phase in the form of suspension, a colloidal phase and substances soluble in water. Coagulability is mainly connected with a physical and chemical stability of this system, conditioned by electrostatic interaction of effluent components ${ }^{2}$. The quantity of those interactions is connected with the electrokinetic potential of the system and charge density. The electrokinetic potential determines the electric charge of the solid phase in the examined solution. In the case of papermaking effluent, the components of the solid phase have negative charge in water suspension and the molecules of the same sign repel each other. The latest retention agents work, producing the flocculation state in a stable suspension through the modification of the surface of the suspended molecules.

The most important, presently used retention agents are synthetic polymers - cationic, anionic and neutral - belonging to four groups. These are polyethyleneimines, polyamines, polyamidoamines and polyacrylamides. All those compounds have a structure of a more or less elongated and branched chain. The retention agents are used at many stages of the technological system. They can be used alone or in dual combinations, making use of their synergetic effect. This rule applies both to organic and inorganic compounds.

The interaction between the cationic retention agents (mainly used in water and effluent systems in paper mills) and the negatively charged molecules of solids in wastewater, can be described by three models:
1. Neutralization of the electric charge - with the neutralizing charge, the anionic charge of molecules is compensated by an addition of a cationic retention agent. The full charge of suspension, expressed by the value of the electrokinetic potential, approaches 0 . As a result the molecules are aggregated and retention is increased. A popular coagulant, used in many wastewater treatment plants - aluminum sulfate behaves according to this rule.

2. Mosaic adhesion - the positively charged molecules, which attract other negatively charged molecules with electrostatic force, are formed as a mosaic, through partial absorption of cationic compounds, on the surface of highly dispersed molecules of the solid phase, through partial absorption of cationic compounds. Polyethyleneimine and low molecular polyamidoamines behave according to this rule.

3. The system of bonds in the form of bridges between the high molecular weight polymers. The system is formed when chains of polymers are sufficiently large to overcome the electrostatic barrier. During the flocculation occurring as a result of polyelectrolyte action according to this rule, the electrokinetic potential differs from 0 , as charge compensation (neutralization) is not needed for this purpose.

Application of modern, synthetic coagulants and flocculants plays a significant role in the production of recycled paper, both when manufacturing the paper from the recycled pulp and processing the contaminated recovered paper into secondary fibres of possibly high quality. Modern technological solutions for the recovered paper processing (including its flotation de-inking and purification stages) require an application and optimization of various chemicals in the de-inking process as well as sludge concentration and dewatering ${ }^{3,4}$.

A few years ago one paper mill in Poland started up a modern installation for the recovered paper processing and de-inking. The production of papermaking stock is entirely based on the recyclable material, mainly old newspapers and scraps from printing works. The installation was erected to manufacture the sanitary papers of high quality, that is with a low content of ashes as well as the optical and strength properties required from a primary fibre based product (cellulose pulp). Particular emphasis was placed on the lowest effluent discharge from the line for the de-inked stock preparation. 


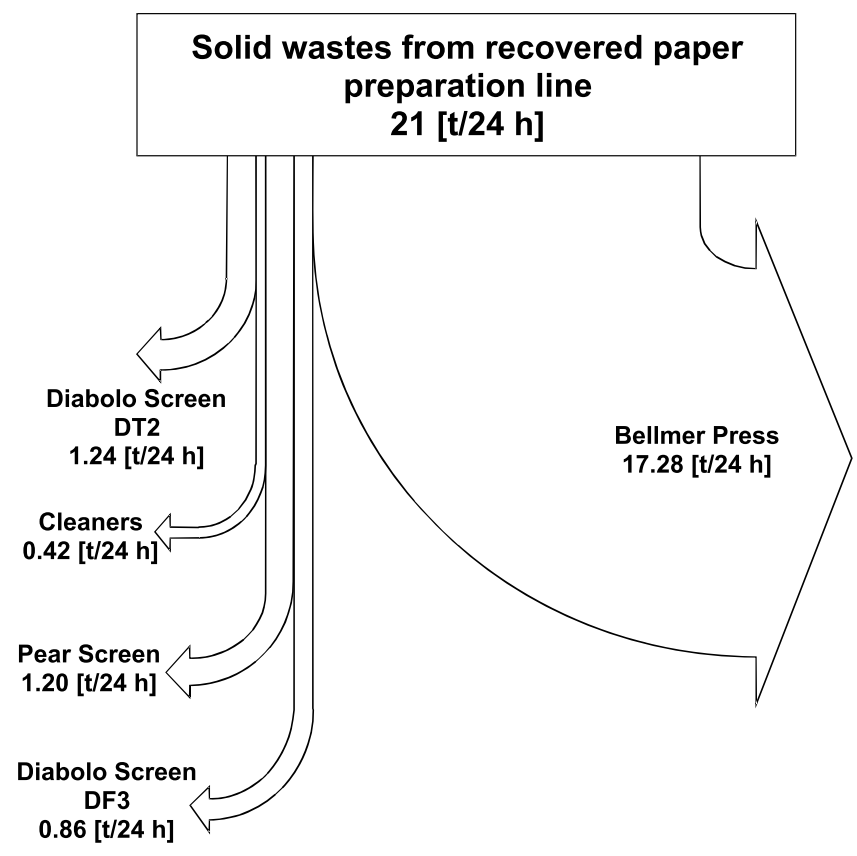

Figure 1. The balance of the wastes from the recovered paper preparation plant

Wastes from the recovered paper processing arising in this technological unit consist of solid contaminants (removed by several types of screens and cleaners) and the after flotation sludge (removed to a dewatering Turbodrain unit and further to a Bellmer thickening press).

As Sankey diagram shows (Fig. 1), the largest amount of waste comes from the Bellmer press. Because of that this is a key to an efficient operation of the entire technological line. The appropriately selected retention aids play the main part in this process. They are used to improve sludge dewatering. The sludge is usually highly diluted and contains the fines that make dewatering difficult to carry out. When selecting the agents (coagulants and flocculants) the press specification has to be considered as well as the cost of the whole operation.

\section{EXPERIMENTAL}

The research work, a part of which is presented here, analyzes the effectiveness of the selected chemicals (coagulants and flocculants) that can support sludge purification and removal after the Bellmer press, in the recovered paper processing line. For this purpose some cationic (emulsion and powder) flocculants were selected and tested. Drainage time factor of the after flotation sludge (transferred into the thickener before the Bellmer press) was selected as a main criterion for the evaluation of the effectiveness of those chemicals. At the first stage of the research the most effective flocculent had been chosen and later its dosage was optimized in the industrial conditions. The following results were determined as criteria for the effectiveness evaluation:

- COD (according to ISO 15705),

- electrokinetic potential (according to Mutek PCD2),

- drainage time factor measured with a Schopper-Riegler apparatus.

Having different types of flocculants, in the form of emulsion and powder, the authors tried to select the agent forming flocs, which settle and filter easily. The first stage of the research estimated the dewatering effect of the following retention aids on the sludge added to the Turbodrain thickener and then to the Bellmer press:
- cationic powder flocculants:

$$
\begin{array}{ll}
\text { - PCY1 } & - \text { PCY2 } \\
\text { - PCY3 } & - \text { PCY4, }
\end{array}
$$

- cationic emulsion flocculants with a straight chain:

$$
- \text { ECX1 - ECX2 }
$$$$
\text { - ECX3 - ECX4, }
$$

- cationic emulsion flocculants with a branched chain:

$$
\begin{array}{ll}
- \text { ECR1 } & - \text { ECR2 } \\
- \text { ECR3 } & - \text { ECR4 }
\end{array}
$$

Different dosages of flocculants from each group were added to the tested sludge. Minimal dewatering time of the constant sludge volume $\left(1000 \mathrm{~cm}^{3}\right)$ in relation to the volume of 600 $\mathrm{cm}^{3}$, measured with the Schopper-Riegler apparatus, was the main criterion for the optimal dosage of each flocculent. The obtained results for the PCY group are shown in Figure 2. As we can see, the PCY3 flocculant turned out to be the most effective powder flocculant from this group.

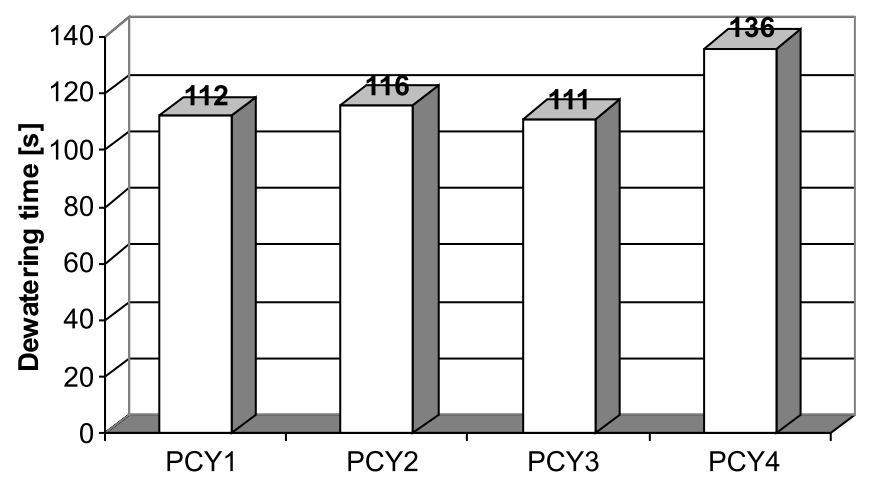

Figure 2. The effectiveness of cationic powder flocculants from the PCY group

Figure 3 shows the results of the dewatering effect of cationic emulsion flocculants with a straight chain (ECX). The ECX4 flocculant turned out to be the most effective. Its optimal dosage shortened the dewatering time of the tested sludge three times when compared to the optimal dosage of the least effective agent from this group, namely ECX1.

Figure 4 illustrates the results of the dewatering effect of cationic emulsion flocculants with a branched chain (ECR). The ECR3 flocculant was the most effective agent. The optimal dosage of this chemical speeds up the dewatering time of the tested sludge four times faster when compared to the optimal dosage of the least effective flocculant from this group (ECR2).

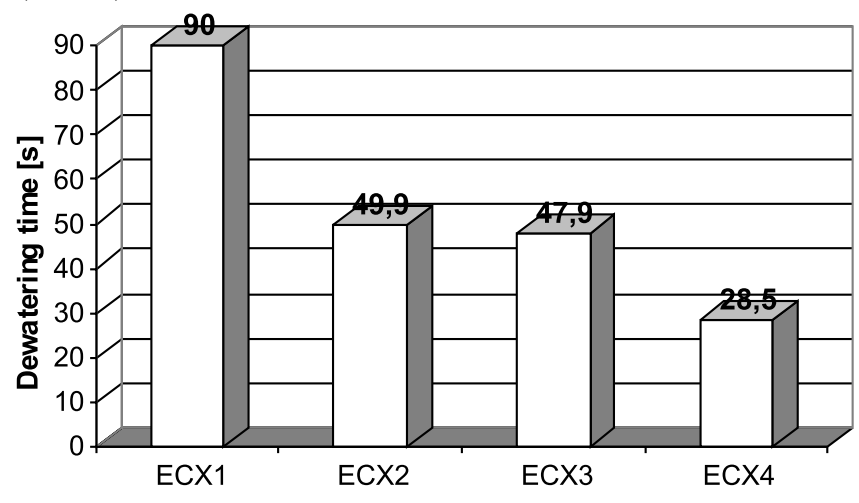

Figure 3. The effectiveness of cationic powder flocculants from the ECX group

The results collected in the first part of the research selected the most effective retention aid. It was the compound with the branched chain ECR3. As Figures 2, 3, 4 show, when compared to the same dosage of the most effective PCY3 powder flocculant, the optimal dosage of ECR3 speeds up the 


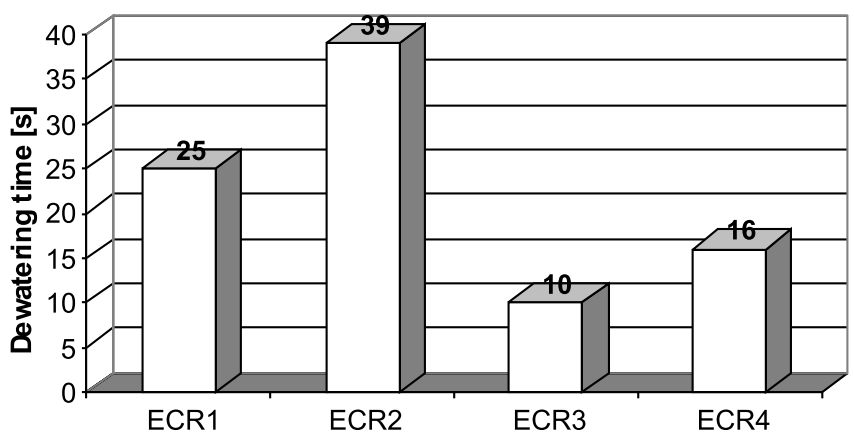

Figure 4. The effectiveness of cationic powder flocculants from the ECR group

dewatering of the tested sludge (transferred into a drying machine before the Bellmer press) over ten times faster and almost three times quicker when compared to ECX3.

The next stage of the research aimed at an exact determination of the ECR3 flocculant in industrial conditions. Due to the fact that ECR3 helped to obtain the shortest dewatering time of the tested sludge, the tests were supplemented by the measurements of COD and the electrokinetic potential. The results are shown in Figure 5 and Figure 6.

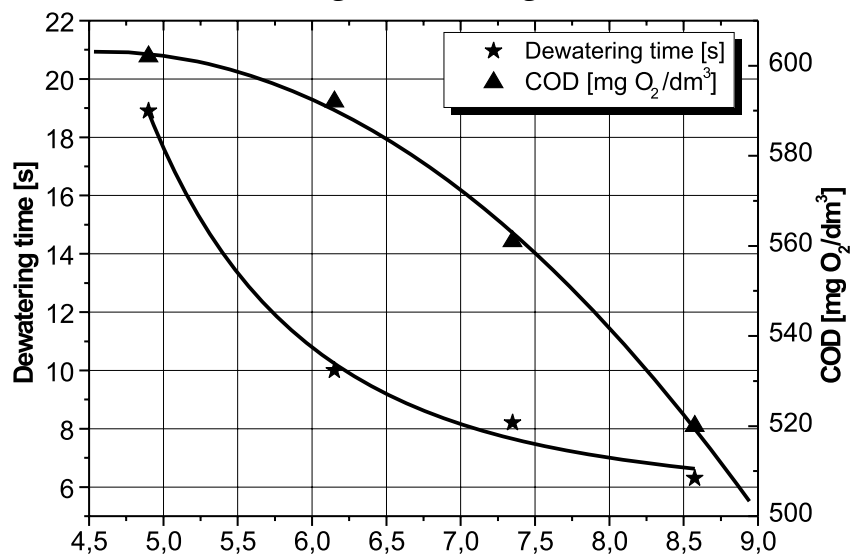

Industrial consumption of the flocculant [kg/t of ab. dry sludge]

Figure 5. Sludge dewatering time before the Bellmer press and decrease in COD in wastewater from the Turbodrain thickener, dependent on the dosage of the flocculant

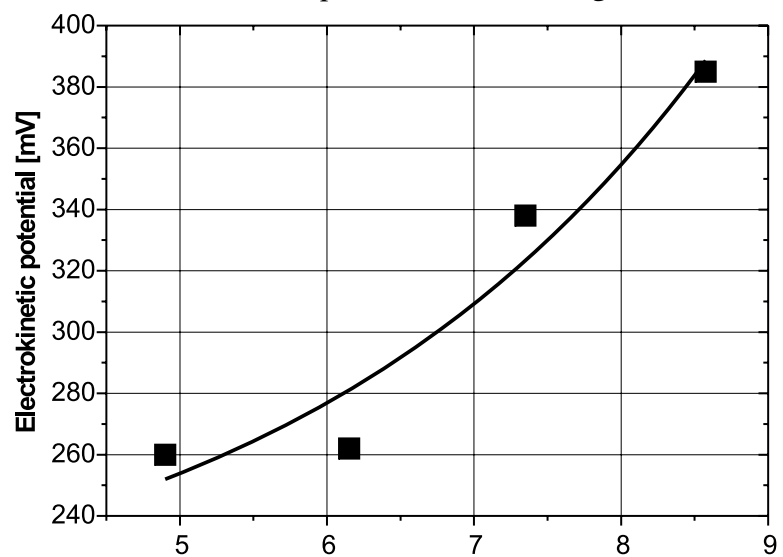

Industrial consumption of the flocculant [kg/t of ab. dry sludge]

Figure 6. The relation between the electrokinetic potential and the flocculant dosage

Flocculant consumption in the industrial conditions was determined giving its dosage in kgs per tonne of the absolutely dry sludge, that is why Figure 5 and Figure 6 present the changes of the parameters, illustrating the properties of the after flotation sludge in the function of the ECR3 dosage expressed in $\mathrm{kg} / \mathrm{t}$ of the absolutely dry dewatered sludge. The increased dosages of the tested retention aid (in the range from 4.8 to $8.5 \mathrm{~kg} / \mathrm{t}$ of the absolutely dry sludge) shortened the dewatering time three times (from 18.9 to $6.3 \mathrm{~s}$ ) and decreased the COD value by $15 \%$ in the wastewater after the thickener (Fig. 5). The increased values of the electokinetic potential show a strong flocculation of the coagulated molecules of the suspension according to the mechanism of creating bonds in the form of bridges by a high molecular weight polymer ECR3. For the flocculation according to this mechanism, charge neutralization of sludge molecules is not necessary, quite the opposite - a certain charged state of their surface is needed.

\section{CONCLUSION}

The obtained results were the base for the cost analysis. Figure 7 shows the dynamics of the dewatering time (the differences between two consecutive dewatering sequences) of the tested sludge as well as the changes in the costs of ECR3 application as a function of its consumption, expressed in $\mathrm{kg}$ / $\mathrm{t}$ of the absolutely dry sludge.

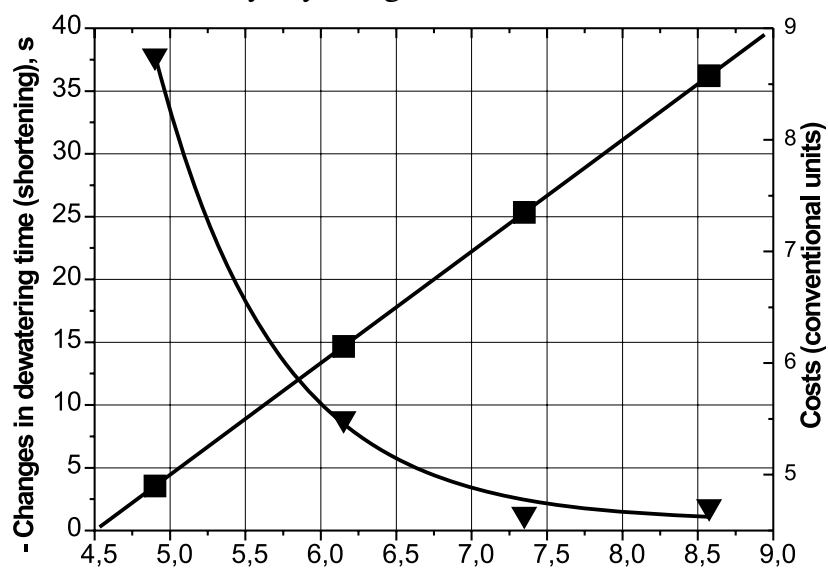

Industrial consumption of the flocculant [kg/t of ab. dry sludge]

Figure 7. A comparison between the shortened dewatering time and the cost of the selected flocculant consumption depending on its dosage

The highest dynamics of sludge dewatering improvement (expressed by the dewatering time in standard conditions) can be observed with ECR3 dosage of $6-6.5 \mathrm{~kg}$ per a tonne of the absolutely dry sludge. Further growth in the consumption of the chemical was less effective and more expensive. As Figure 7 demonstrates the cost grows linearly along with a higher dosage of the flocculant. As the results listed in Table 1 and illustrated in Figures $6-8$ show, the ECR3 dosage of $6.15 \mathrm{~kg}$ per tonne of the absolutely dry sludge, was considered the most effective and economical.

The long-term analyses of the tested line proved that the retention aid and its dosage were selected correctly.

\section{LITERATURE CITED}

(1) Au C. O., Thorn I.: Applications of Wet End Chemistry, Blackie Academic and Professional, 1995.

(2) Przybysz K., Rybicki E., Czechowski J.: Electrokinetic Potential Studies of Dissolved Substances Washed Out in the Papermaking Process, Fibers and Textiles in Eastern Europe, 2002, 65, 10.

(3) Koppermuller J.: Modern recycled fibers' preparation for packaging papers, Wochenbl. Papierfabr. 1995, 26, 123.

(4) Doshi M., Dyer J. M.: Paper Recycling Challenge, vol. 3 - Process Technology, Doshi and Associates Inc. 1998.

(5) Czechowski J., Olejnik K.: „Ocena odpadów z linii technologicznej przerobu makulatury z uwzględnieniem zawartości metali ciężkich” Przemysł Chemiczny 2003, 82, 1121. 